\title{
Inserção da celulose brasileira e de seus principais concorrentes no mercado internacional
}

Inserting the brazilian wood pulp and its main competitors in the international market

Insertando de celulosa brasileño y sus principales competidores en el mercado internacional

Mateus Monteiro Piedade Lyrio ${ }^{1}$

Naisy Silva Soares ${ }^{2}$

Lyvia Julienne Sousa Rêgo ${ }^{3}$

DOI: $10.5752 /$ P.1809-6182.2021v18n1pX

Recebido em: 26 de novembro de 2020

Aprovado em: 03 de julho de 2021

\section{Resumo}

O presente artigo teve como objetivo classificar a inserção do segmento brasileiro de celulose no comércio internacional, entre 1970 e 2019, e de seus principais concorrentes mundiais: Estados Unidos, China e Canadá. Verificou-se que o Brasil foi o único pais que apresentou alta eficiência em todas as décadas analisadas.

Palavras-chaves: posicionamento; competitividade; setor de celulose e papel.

\begin{abstract}
This article aimed to classify the insertion of the Brazilian wood pulp segment in international trade, between 1970 and 2019, and of its main global competitors: the United States, China and Canada. It was found that Brazil was the only country that showed high efficiency in all the analyzed decades.
\end{abstract}

Keywords: positioning; competitiveness; wood pulp and paper sector.

\section{Resumen}

Este articulo tuvo como objetivo clasificar la inserción del segmento de celulosa brasileño en el comercio internacional, entre 1970 y 2019, y de sus principales competidores globales: Estados Unidos, China y Canadá. Se encontró que Brasil fue el único país que mostró alta eficiencia en todas las décadas analizadas.

Palabras Clave: posicionamiento; competitividad; sector de la celulosa y el papel.

\footnotetext{
1 Economista e mestrando em economia regional e políticas públicas na Universidade Estadual de Santa Cruz. E-mail: mateus_ monteiro123@hotmail.com. Orcid: 0000-0002-7589-8455

${ }^{2}$ Economista e doutora em Ciência Florestal. Professora doutora do departamento de ciências econômicas da Universidade Estadual de Santa Cruz. E-mail: naisysilva@yahoo.com.br. Orcid: 0000-0001-6855-0218

${ }^{3}$ Engenheira florestal e doutora em Ciência Florestal. Professora da Universidade Federal do Sul da Bahia. E-mail: lyviajulienne@ hotmail.com. Orcid: 0000-0001-7043-6860
} 


\section{Introdução}

A produçáo de celulose tem se consolidado como um dos principais produtos da indústria florestal. De acordo com Zaeyen (1986), foram três os fatores que consolidaram as bases da indústria de celulose e papel brasileira: (i) a política de incentivos fiscais de 1966 (Lei no 5.106), que, ao permitir a dedução de Imposto de Renda para investimentos em projetos de reflorestamento aprovados pelo Instituto Brasileiro de Desenvolvimento Florestal (IBDF), propiciou a expansão dos maciços florestais de espécies exóticas no Brasil, especialmente de pinus e eucalipto; (ii) a fixação pelo Banco Nacional de Desenvolvimento Econômico e Social (BNDES), em 1968, de níveis mínimos de escala de produçáo para projetos que desejassem apoio financeiro; e (iii) a fixação pelo Conselho de Desenvolvimento Econômico (CDE), em 1972, de novos níveis mínimos de escala de produção, os quais foram adotados também pelo BNDES e resultaram no aumento expressivo da produção brasileira e no início das exportaçôes.

Dentre os programas do governo federal para o segmento de celulose e papel que se destacaram, citam-se: Primeiro Programa Nacional de Papel e Celulose (I PNPC) e Segundo Programa Nacional de Papel e Celulose (II PNPC). O I PNPC foi criado em 1974 para impulsionar o aprimoramento da tecnologia florestal e alcançar a autossuficiência tanto em papel quanto em celulose, possibilitando a geração de excedentes exportáveis (JUVENAL; MATTOS, 2002), to de celulose e papel (II deral para o setor que se destacaram, citam-se .

Data de 1985, a criação do II PNPC com principal objetivo de obter linhas de financiamento de longo prazo do BNDES para viabi- lizar um novo ciclo de investimentos (SOTO, 1992). Foi com o II Programa Nacional de Desenvolvimento que foram ampliadas as bases para a indústria nacional de celulose, a fim de reduzir a dependência em relação a fontes externas (JUVENAL; MATTOS, 2002).

Assim, até meados da década de 1950 cerca de $70 \%$ da celulose necessária para a produção de papel ainda era importada. A partir da década de 1960 o país passou a gerar excedentes exportáveis, e na década seguinte o país passou a obter saldos positivos na balança comercial do setor de celulose (HILGEMBERG e BACHA, 2000).

Em 2019, o Brasil passou a ser o segundo maior produtor de celulose do mundo, produzindo 20.277 mil toneladas, ficando atrás apenas dos Estados Unidos, sendo que 74\% da produção nacional foi destinada ao comércio internacional (FOOD AND AGRICULTURE ORGANIZATION - FAO, 2020; INDÚSTRIA BRASILEIRA DE ÁRVORES - IBA, 2019).

O crescimento das exportaçóes brasileiras de celulose está associado também ao efeito competitividade do segmento no comercio internacional e o crescimento da produção é resultado do investimento em tecnologia e pesquisa e do crescimento da demanda internacional (ROCHA e SOARES, 2014).

Observando os principais concorrentes do Brasil na produção de celulose é possível observar diferentes tendências. $\mathrm{O}$ setor de celulose no Estados Unidos apresentou baixo crescimento entre 2010 e 2019, em média a produção de celulose do país cresceu $0,645 \%$ ao ano, enquanto que no Brasil cresceu em média $4,17 \%$ ao ano e no Canadá recuou em média 0,27\% ao ano. Em 2019, os Estados Unidos exportou US\$ 5.596 .710 mil, tendo uma re- 
tração de 6,04\% em relação a 2018, o Canadá exportou $6,06 \%$ menos em relação a 2018 , obtendo US\$ 47.576,37 mil (FAO, 2020).

Em contraste aos países da América do Norte, a produção de celulose na China vem crescendo. Entre 2010 e 2019 a produçáo do país cresceu em média $10,85 \%$ ao ano, uma taxa de crescimento superior à evidenciada no Brasil no mesmo período ( $4,17 \%$ ao ano). No comercio internacional o país obteve US\$122.693,00 mil em exportaçóes de celulose (FAO, 2020).

O Brasil nos últimos anos tem mostrado capacidade de competir em um nível cada vez mais elevado, mesmo que não haja políticas públicas destinadas ao setor. Entretanto, o cenário externo nem sempre é favorável ao crescimento da atividade produtiva. É necessário realizar uma classificação especifica levando em consideração a participação do país no comercio mundial do produto bem como a importância do produto para comércio mundial.

Diante disto, o presente trabalho tem como objetivo classificar a inserção do segmento brasileiro de celulose no comércio internacional, de 1970 a 2019, e de seus principais concorrentes no mercado mundial: Estados Unidos, China e Canadá; e destacar o posicionamento e a eficiência do segmento de celulose para cada país no mercado internacional.

\section{Métodos e dados}

Para exercício de classificação utilizou-se a metodologia de Fajnzylber e Mandeng (1991), que analisaram a estrutura exportadora de países, levando em consideração sua competitividade e eficiência no comércio internacional utilizando como medida de competitividade a participação de determinado setor produtivo nas importaçôes mundiais. E em termos de eficiência os autores ponderam a participação relativa de um país nas vendas de determinado segmento produtivo (FAJNZYLBER E MANDENG, 1991).

As posiçóes e as variaçóes em termos de competitividade e eficiência na "matriz de competitividade" configuram uma situação favorável ou desfavorável, enquanto a variação de eficiência de um país expressa alta ou baixa eficiência relativa (FAJNZYLBER E MANDENG, 1991; SANTOS et al., 2016).

Assim, há quatro situaçôes possíveis para o posicionamento de um país: ótima, onde a posição relativa do produto é favorável e o país possui alta eficiência; vulnerabilidade, onde o país possui alta eficiência relativa, mas a posição do produto é desfavorável; oportunidade perdida, quando a posição do produto é favorável mas o país possui baixa eficiência relativa; e em retrocesso, onde associada a uma posição desfavorável do produto o país apresenta baixa eficiência relativa (Figura 1) (FAJNZYLBER, MANDENG, 1991; SANTOS et. al., 2016).

Figura 1 - Matriz de competitividorde

\begin{tabular}{|c|c|c|c|}
\hline \multirow{4}{*}{ 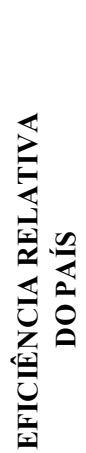 } & & \multicolumn{2}{|c|}{ RELATIVA POSIČÃO DO PRODUTO } \\
\hline & & DESFÁ VORAVEL & FAVORÁVEL \\
\hline & BAIXA & $\begin{array}{l}\text { SITUAÇÃO DE } \\
\text { RETROCESSO }\end{array}$ & $\begin{array}{c}\text { SITUAÇÃO DE } \\
\text { OPORTUNIDADES } \\
\text { PERDIDAS }\end{array}$ \\
\hline & & $\begin{array}{c}\text { SITUAÇÃO DE } \\
\text { VULNERABILIDADE }\end{array}$ & SITUAÇÃO ÓTIMA \\
\hline & ALTA & & \\
\hline
\end{tabular}

Fonte: Fajnzylber e Mandeng (1991)

Segundo Carvalho e Silva (2005) a posição relativa do produto é expressa por $s i$, e refere-se à participaçáo das importaçóes mundiais produto, aqui a celulose, nas importaçôes mundiais:

$$
s_{i}=\frac{i m p . \text { mundiais celulose }(M i)}{\text { imp. mundiais }(M)}
$$


Uma variação positiva ou igual a zero em representa um aumento ou manutenção da participação da celulose nas importaçôes mundiais, configurando uma posição favorável. Uma variação negativa reflete um posicionamento desfavorável em virtude da perda de participação no comércio internacional.

A eficiência para Carvalho e Silva (2005) é expressa por, e significa a participação relativa das exportaçóes de determinado produto de um dado país nas vendas mundiais do produto. Para celulose tem-se:

$$
s_{i j}=\frac{\text { exp. celulose do país }(X i j)}{\text { imp.mundiais de celulose }(M i)}
$$

Uma variação positiva ou igual a zero de reflete um ganho de competitividade no mercado internacional da celulose. Caso ocorra uma variação negativa no o país teve uma baixa eficiência na comercialização da celulose.

Tal metodologia avalia a inserção de determinado país no mercado internacional num certo instante no tempo, captando modificaçóes em curto prazo e explicando determinadas tendências do segmento do país. As variaçóes observadas indicam ganhos ou perdas de mercados, que ocorrem simultaneamente com modificaçôes nas tendências mundiais de demanda e oferta por determinado produto (PENA, 2004).
Os dados foram obtidos por meio da base de dados FAOSTAT disponibilizada pela Food and Agriculture Organization e na Organização Mundial do Comércio (OMC). O período de análise foi 1970 a 2019 (FAO, 2020; OMC, 2020).

A análise dos resultados foi realizada por décadas para verificar a evolução de uma década para outra no comércio internacional da celulose. Assim, os valores de si e sij foram estimados para cada ano e, posteriormente, foi feita uma média desses indicadores para cada década. Em segui$\mathrm{da}$, foi estimada a variação desses indicadores de uma década para outra. Os resultados apresentados sobre a variação dos indicadores iniciam-se a partir da década de 1970, pois as estimativas do si e sij iniciam-se em 1960, devido à indisponibilidade de dados de períodos anteriores.

Buscou-se realizar a classificação dos quatro maiores produtores e exportadores mundiais de celulose nos últimos anos, sendo respectivamente Estados Unidos, Brasil, China e Canadá, conforme FAO (2020).

\section{Resultados e discussão}

O segmento mundial de celulose vem apresentando uma trajetória ascendente desde a década de 1960, com um crescimento médio anual de 2,01\% ao ano (Figura 2).

Figura 2 - Produção mundial de celulose entre 1961 e 2019.

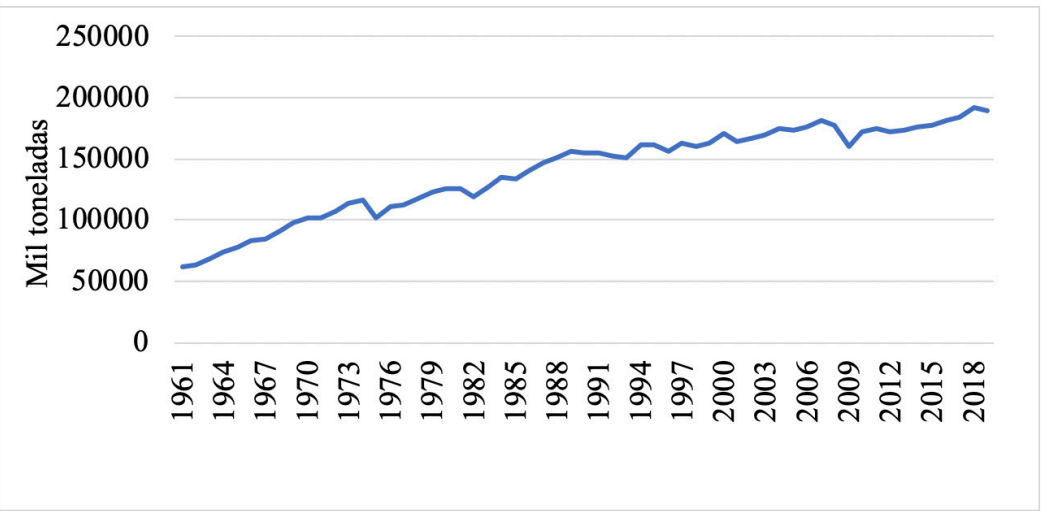


Foi possível observar diferentes tendências produtivas do segmento em cada país. A participação dos Estados Unidos e Canadá na produção mundial de celulose diminuíram ao longo dos anos, enquanto a participação de países como Brasil e China cresceu (Figura 3).

O Brasil a partir de 2015 passou a ter maior peso na produção total mundial de celu- lose superando o Canadá. A China segue apresentando uma tendência semelhante e tende a também superar o Canadá nos próximos anos. $\mathrm{Na}$ década de 2010 a produção de celulose na China cresceu em média $4,60 \%$ ao ano, enquanto o Canadá tem apresentado um decrescimento de $1,17 \%$ ao ano (Tabela 3).

Figura 3 - Participação percentual dos Estados Unidos, Canadá, Brasil e China na produção mundial total de celulose, entre 1961 e 2019.

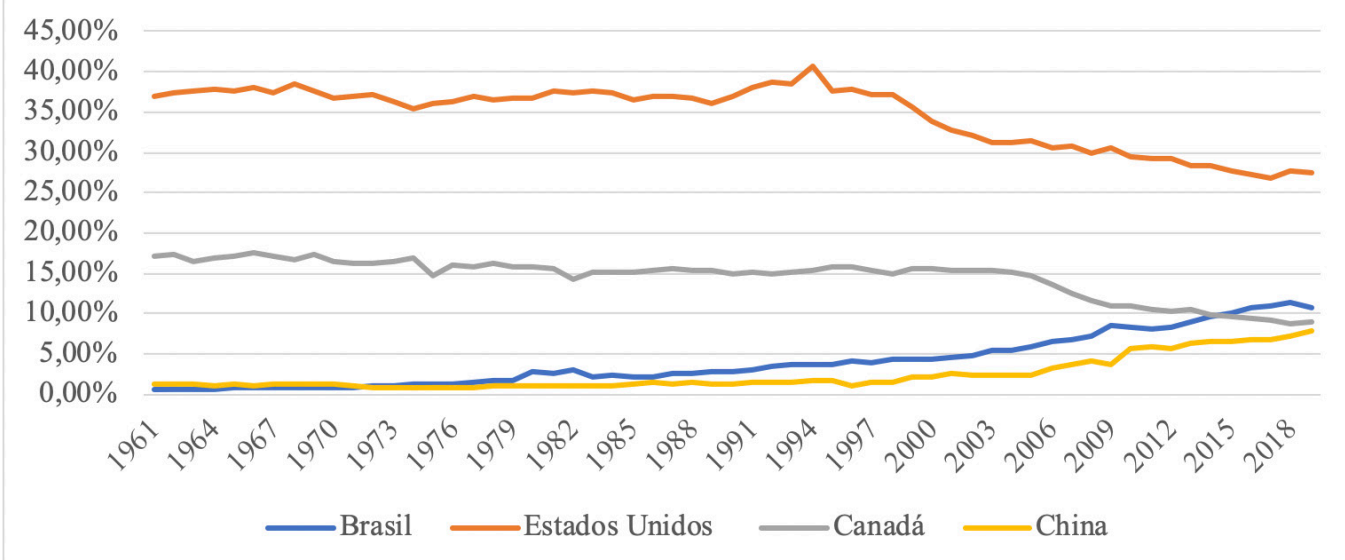

Fonte: Elaboração própria a partir de dados da FAO (2020).

Em 1970 as importaçôes de celulose representaram, aproximadamente, $0,80 \%$ das importaçôes mundiais, mostrando que a celulose havia ganhado notoriedade no comércio internacional. Porém, desde a década de 1970 a participação da celulose nas importaçôes mundiais vem apresentando uma trajetória, que embora apresente oscilaçóes, expressa uma nítida tendência de queda (Figura 4). A participação da celulose no comércio internacional vem diminuindo ao longo dos anos.

Figura 4 - Participação percentual dass importações de celulose nas importações mundiais entre 1961 e 2019.

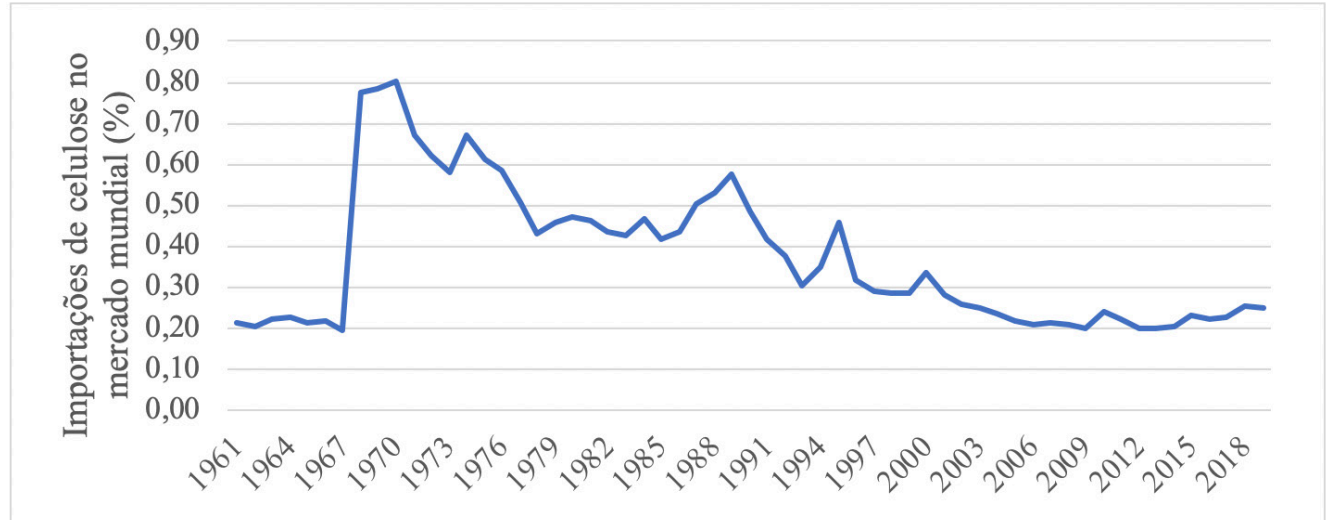


A década de 1970 representou o período de maior participação da celulose no comercio internacional, em média as importações de celulose nessa década corresponderam a 0,59\% das importaçôes mundiais. Essa participação da celulose no comercio internacional diminuiu nas décadas seguintes chegando na década de 2010 a representar em média $0,23 \%$ das importações mundiais (Figura 4). Isso pode ser explicado pelo crescimento da produçáo nos principais países consumidores mundiais, bem como pelas barreiras comerciais.

Sobre o posicionamento, eficiência e situação do Brasil e de seus principais concorrentes no comércio internacional de celulose, de 1960 a 2019, por década, estes se encontram na Tabela 1 .

Tabela 1 - Posicionamento, eficiência e situação do Brasil e de seus principais concorrentes no comércio internacional de celulose de 1970 a 2019, por década.

\begin{tabular}{|c|c|c|c|c|c|}
\hline Década & Itens & Brasil & Estados Unidos & Canadá & China \\
\hline \multirow{5}{*}{1970} & $\Delta$ Si médio & 0,289 & 0,289 & 0,289 & 0,289 \\
\hline & Posicionamento & Favorável & Favorável & Favorável & Favorável \\
\hline & $\Delta \mathrm{Sij}$ médio & 0,01 & $-0,06$ & 0,10 & 0,0014 \\
\hline & Eficiência & Alta & Baixa & Alta & Alta \\
\hline & Situação & Ótima & $\begin{array}{l}\text { Oportunidades } \\
\text { Perdidas }\end{array}$ & Ótima & Ótima \\
\hline \multirow{5}{*}{1980} & $\Delta$ Si médio & $-0,123$ & $-0,123$ & $-0,123$ & $-0,123$ \\
\hline & Posicionamento & Desfavorável & Desfavorável & Desfavorável & Desfavorável \\
\hline & $\Delta$ Sij médio & 0,03 & 0,03 & $-0,004$ & 0,001 \\
\hline & Eficiência & Alta & Alta & Baixa & Alta \\
\hline & Situação & Vulnerabilidade & Vulnerabilidade & Retrocesso & Vulnerabilidade \\
\hline \multirow{5}{*}{1990} & $\Delta$ Si médio & $-0,115$ & $-0,115$ & $-0,115$ & $-0,115$ \\
\hline & Posicionamento & Desfavorável & Desfavorável & Desfavorável & Desfavorável \\
\hline & $\Delta$ Sij médio & 0,02 & 0,01 & $-0,02$ & $-0,0004$ \\
\hline & Eficiência & Alta & Alta & Baixa & Baixa \\
\hline & Situação & Vulnerabilidade & Vulnerabilidade & Retrocesso & Retrocesso \\
\hline \multirow{5}{*}{2000} & $\Delta$ Si médio & $-0,115$ & $-0,115$ & $-0,115$ & $-0,115$ \\
\hline & Posicionamento & Desfavorável & Desfavorável & Desfavorável & Desfavorável \\
\hline & $\Delta \mathrm{Sij}$ médio & 0,04 & $-0,04$ & $-0,06$ & $-0,0012$ \\
\hline & Eficiência & Alta & Baixa & Baixa & Baixa \\
\hline & Situação & Vulnerabilidade & Retrocesso & Retrocesso & Retrocesso \\
\hline \multirow{5}{*}{2010} & $\Delta$ Si médio & $-0,016$ & $-0,016$ & $-0,016$ & $-0,016$ \\
\hline & Posicionamento & Desfavorável & Desfavorável & Desfavorável & Desfavorável \\
\hline & $\Delta$ Sij médio & 0,05 & 0,00 & $-0,07$ & 0,0007 \\
\hline & Eficiência & Alta & Alta & Baixa & Alta \\
\hline & Situação & Vulnerabilidade & Vulnerabilidade & Retrocesso & Vulnerabilidade \\
\hline
\end{tabular}

Fonte: Resultados da Pesquisa. 
Na década de 1970, Brasil, Estados Unidos, Canadá e China estavam em uma posição favorável no comércio internacional da celulose. Esses países apresentaram alta eficiência nessa década e se enquadraram em uma situação ótima no comércio internacional da celulose, exceto os Estados Unidos que apresentou baixa eficiência se enquadrando numa situação de oportunidade perdida (Tabela 1 ).

O bom desempenho do Brasil no comércio internacional da celulose na década de 1970 caracterizando uma situação ótima, pode estar associado às políticas públicas destinadas ao segmento florestal e de celulose como a política de incentivos fiscais ao reflorestamento que vigorou de 1966 a 1988, ao aproveitamento de novas espécies florestais e ao uso da celulose de fibra curta de forma integral na produção de papel. Destacando que na década de 1970 o governo brasileiro implementou o I Programa Nacional de Papel e Celulose que buscou a auto suficiência produtiva do setor e a geração de excedentes exportáveis, ainda havia o incentivo as plantas produtivas que apresentassem condiçôes favoráveis para participar no comércio internacional (BNDES, 1991; HILGEMBERG e BACHA, 2000; ANTONANGELO E BACHA, 1998; SOTO, 1992).

A alta eficiência e a situação favorável do Canadá no comércio internacional da celulose resultando numa situação ótima, pode ser resultado de mudanças no segmento de celulose do país a partir da Segunda Guerra Mundial onde houve o crescimento da fabricação química da celulose possibilitando o uso de outras espécies florestais na produção de celulose. Além da diversificação da produção e do mercado, impulsionada, especialmente, pelo crescimento da demanda por celulose por parte da Europa e da Ásia (BOGDANSKI, 2014).
Embora a China tenha apresentado alta eficiência, posicionamento favorável e situação ótima no comércio internacional da celulose na década de 1970, o segmento possuía como característica a produçáo em maior quantidade de celulose provenientes de insumos não lenhosos como bamboo, cana e palha de arroz, baixa escala produtiva e baixa tecnologia de processamento. Contudo, por um fator estrutural do país, a partir do final da década de 1970 a China passa a ter maior participação no comércio internacional. Em meados da década o país passou por reformas na economia, um processo de modernização na indústria e agricultura, maior interesse em investimentos estrangeiros e crescimento da participação no comércio exterior o que pode está explicando o bom desempenho da China no comércio internacional da celulose (LI, LOU E MCCARTY, 2002; ZHUANG, DING E LI, 2005; ANDRADE, NARETTO E LEITE, 2015).

Os Estados Unidos, por sua vez, foi o único país que apresentou uma situação de oportunidades perdidas, na década de 1970 (Tabela 1). Nesse período, o volume de celulose exportado pelo país caiu. Em 1979 a produção de celulose do país foi de 45.318 mil toneladas, $21,44 \%$ maior do que 1970 , mas o volume exportado no ano de 1979 foi de 2.624,4 mil toneladas, 6,55\% menor em relação ao início da década (INCE et. al., 2001; FAO, 2020). Isso pode ser devido a produtividade florestal nos Estados Unidos ser menor e o tempo de produção maior que em países como o Brasil (SOARES, 2010).

$\mathrm{Na}$ década de 1980, o posicionamento da celulose passou a ser desfavorável no comércio internacional para os países em análise. Nessa década o Estados Unidos apresentou alta eficiência na produção de celulose, assim como 
Brasil e China. Esses três países se enquadraram em uma situação de vulnerabilidade. O Canadá apresentou baixa eficiência produtiva, apresentando uma situação de retrocesso (Tabela 1).

Embora a celulose tenha apresentado menor participação no comércio internacional o segmento no Brasil estava em ascensão, apresentando maquinário compatível a tecnologia empregada no mundo e com maior integração ao segmento florestal. Nessa década a indústria ainda contou com a implementação do II Programa Nacional de Papel e Celulose que propiciou um novo ciclo de investimento ao setor (SOTO, 1992; BNDES, 1991; HILGEMBERG E BA$\mathrm{CHA}, 2000$ ). Esses fatores podem estar explicando a alta eficiência brasileira no comércio internacional de celulose na década de 1980.

A China, embora ainda produzisse celulose em maior parte proveniente de materiais não lenhosos, ainda era favorecida pela ascensão econômica e maior inserção no comércio internacional. A China possuía uma grande demanda interna por celulose, em 1989 o país produziu 2.077 mil toneladas de celulose, volume 54,6\% maior em relação 1980 , sendo $96 \%$ consumida no mercado interno. As exportaçóes de celulose da China cresceram ao longo da década 1980 e em 1989 o país exportou 83 mil toneladas de celulose, cerca de $4 \%$ da produção nacional, obtendo US\$ 59,94 mil em exportaçôes. Esse volume exportado foi $276,67 \%$ maior em relação a 1980 (FAO,2020).

As exportaçóes de celulose do Estados Unidos seguiram uma trajetória ascendente ao longo da década de 1980. Em 1989, o país destinou $10 \%$ da sua produçáo nacional ao mercado internacional, isto é US\$ 3.520,71 mil. Reflexo da expansão produtiva evidenciada entre 1970 e 1980, período onde a capacidade produtiva dos setores de papel e celulose teve crescimento a uma taxa de $2,4 \%$ ao ano (INCE et. al., 2001).

O Canadá apresentou uma situação de retrocesso influenciado por um processo de estagnação do segmento de papel entre meados da década de 1970 e 1980 . O efeito é sentido a partir de uma queda das exportaçóes de celulose para o Estados Unidos e também pelo uso de papel reciclado para produção de papel na indústria (BOGDANSKI, 2014).

$\mathrm{Na}$ década de 1990 todos os países em análise apresentaram posicionamento desfavorável no comércio internacional da celulose. Porém, Brasil e Estados Unidos apresentaram alta eficiência produtiva e estiveram em uma situação de vulnerabilidade desfavorável no comércio internacional da celulose. Enquanto Canadá e China apresentaram baixa produtividade e uma situação de retrocesso desfavorável no comércio internacional da commodity (Tabela 1).

Nesse período o volume de exportação do Brasil cresceu expressivamente, em 1999 o país exportou 1.033,4 mil toneladas de celulose, um crescimento de 301\% em relação a 1990 . O segmento ainda contava com o apoio do II Programa Nacional de Papel e Celulose. Em 1990 cerca de $24 \%$ da produção nacional foi exportada, em 1999 esse percentual passou a ser de 43,7\% (FAO, 2020), o que pode estar explicando a situação do país no comércio internacional da celulose nessa época.

O Estados Unidos manteve a competitividade no comércio internacional de celulose, que foi impulsionada muito mais pela alta do preço a partir da segunda metade da década do que pelo volume comercializado. O país apresentava um mercado pulverizado, atendia cerca de 100 países, sendo o principal destino a Europa e Ásia (USITC, 2002). 
A situação de retrocesso do Canadá pode estar associada a maior comercializaçáo de fibra reciclada e da celulose química. O país teve aumento no volume exportado ao longo da década, em 1999 foram 11.649 mil toneladas de celulose exportadas, $47,8 \%$ superior a 1990 , rendendo US\$ 5.018,15 mil, valor 4,12\% inferior a 1990 (BOGDANSKI, 2014; FAO, 2020).

A China passou a perder competitividade em virtude da baixa qualidade de sua celulose ainda em grande parte produzida por material não lenhoso que prejudicavam o país no comércio internacional da celulose. A falta de insumos florestais é um dos principais fatores para produção de produtos de menor qualidade no país, isso afetava inclusive a indústria de papel, que passou a demandar maior volume de celulose no mercado internacional (ZHUANG, DING E LI, 2005).

Nas duas primeiras décadas do século XXI a celulose apresentou um posicionamento desfavorável no comércio internacional da celulose para todos os países considerados na análise. De 2000 a 2009, apenas o Brasil apresentou alta eficiência no comércio internacional da celulose e os seus principais concorrentes no comércio internacional apresentaram baixa eficiência. Assim, o Brasil encontrou-se numa situação de vulnerabilidade e os seus concorrentes em situação de retrocesso nesse comércio (Tabela 1).

No caso brasileiro, ao longo da década, em média, $51,27 \%$ da produção anual da celulose foi destinada ao comercio internacional. O segmento deixou de ter apoio direto de políticas públicas, mas passou a ter apoio do Programa Nacional de Florestas que possui como instrumento a criação de linhas de crédito para a atividade florestal no país. A competitividade do segmento está atrelada a capacidade de investimento das empresas do segmento em tecnologia e pesquisa (BRASIL, 2000; FAO, 2020; ROCHA E SOARES, 2014).
Os Estados Unidos, China e Canadá apresentaram baixa eficiência e se enquadraram em uma situação de retrocesso. No caso dos Estados Unidos uma justificativa se dá pela desaceleração do segmento de papel, papeláo e celulose. A taxa de crescimento anual da capacidade produtiva americana da celulose reduziu de 2,4\% entre 1970 e 1980 para 1,9\% entre 1990 e 2000. A capacidade reduzida do segmento e a força da moeda no comércio internacional influenciaram as exportaçôes do país. No final da década o país ainda foi influenciado pela forte recessão entre 2007 e 2009 (INCE et al, 2001; BOGDANSKI, 2014).

A China apresentava limitações em termos de produtividade, o que resultou na intervenção estatal no processo de reflorestamento como uma alternativa a produção de celulose. Entretanto, os subsídios diretos e indiretos por parte do governo podem resultar na competitividade das empresas (BARR e COSSALTER, 2004).

A situação de retrocesso do Canadá pode ser devido à recessão global entre 2007 e 2009, mas também a mudanças no consumo de papel na América do Norte, especialmente na demanda de papéis gráficos em virtude do crescimento da concorrência da mídia digital, pelas ações de conservação de papel e alteraçôes nos hábitos de leitura (BOGDANSKI, 2014).

De 2010 a 2019, o Brasil e seus principais concorrentes no mercado internacional da celulose apresentaram posicionamento desfavorável no comércio internacional deste segmento. Por outro lado, o Brasil, Estados Unidos e China apresentaram alta eficiência e estiveram em uma situação de vulnerabilidade. Já o Canadá apresentou baixa eficiência e situação de retrocesso (Tabela 1). O segmento da celulose no Brasil conseguiu manter sua competitividade em virtude dos investimentos privados 
em pesquisa e tecnologia, praticamente não contando com apoio estatal nessa área. O país atingiu o patamar de maior exportador do produto apoiado em investimentos em tecnologia e pesquisa que buscam o aumento de produtividade e considerável aumento da comercialização para países como a China (SOARES, 2014; FAO, 2020).

No caso do Estados Unidos a alta eficiência pode ser associada a reorganização do segmento produtivo no país atendendo a demanda interna e tornando-se mais ativa no cenário internacional. Enquanto na China pode ser pelo fomento do plantio em larga escala de espécies florestais como o eucalipto por parte das empresas e pelo próprio governo nacional que buscava reduzir o déficit proporcionado pela importação de celulose pelo segmento de papel ainda na década anterior. O segmento também foi favorecido pelo crescimento econômico vivenciado pelo país ao longo de toda década (BARR E COSSALTER, 2004; MORRISON, 2019).

O Canadá foi o único país nessa década a apresentar baixa eficiência e se enquadrou em uma situação de retrocesso. Essa situação se dá pela dependência que se tinha do mercado do Estados Unidos que continuou a demandar menor quantidade do produto canadense ao longo da década. $\mathrm{O}$ segmento ainda sentia os efeitos negativos da crise do final da década anterior (BOGDANSKI, 2014).

\section{Considerações finais}

Com base nos resultados obtidos, evidenciou-se que o Brasil, Estados Unidos, China e Canadá apresentam classificaçóes distintas no comércio internacional da celulose ao longo das décadas analisadas.
Verificou-se que o Brasil foi o único país que apresentou alta eficiência em todas as décadas analisadas e que apenas na década de 1970 o Brasil e seus principais concorrentes no comércio internacional da celulose apresentaram posicionamento favorável.

Em outras palavras, o Brasil foi o único país dentre os analisados que apresentou ganho de competitividade no mercado internacional da celulose em todo o período considerado. Estados Unidos, Canadá e China apresentaram-se competitivos em alguns períodos.

\section{Referências}

ANDRADE, I. de O.; NARETTO, N. de A.; LEITE, A. W. A dinâmica das relaçóes econômicas entre Brasil e China: uma análise do período (2000-2015). Boletim de Economia e Política Internacional, Brasília, n. 21, set-dez, 2015.

ANTONANGELO, A.; BACHA, C. J. C. As fases da Silvicultura no Brasil. Revista Brasileira de Economia: Rio de Janeiro, 1998.

BARR, C.; COSSALTER, C. China's development of a plantation-basead wood pulp industry: government policies, financial incentives, and investment trends. Internacional Forestry Review, v. 6, n. 3-4, p. 267-281, 2004.

BNDES. A participaçáo do Sistema BNDES na evoluçáo do setor de papel e celulose no Brasil. BNDES: Rio de Janeiro, 1991.

BOGDANSKI, B. E. C. The rise and fall of the Canadian pulp and paper sector. The Forestry Chronicle, Mattawa, v. 90, n. 6, 2014

CARVALHO, M. A. de. SILVA, C. R. L. da. Vulnerabilidade do Comércio Agrícola Brasileiro. Economia e Sociologia Rural, Brasília, v. 43, n. 1, 2005.

FAJNZYLBER, F. International insertion and institutional renewal. CEPAL Review, v. 44, p. 137-166, 1991.

FOOD AND AGRICULTURE ORGANIZATION OF THE UNITED NATIONS (FAO). Forestry Production and Trade. 2014. Disponível em: http://www.fao.org/faostat/en/\#data/FO. Acesso em: ago. 2020.

HILGEMBERG, E. M.; BACHA, C. J. C. A evolução da indústria brasileira de celulose e sua atuação no mercado mundial. Análise Econômica, Porto Alegre, v. 19, n. 36, 2000.

INCE, P. J.; et. al. Uniteed States paper, paperboard, and Market pulp capacity trends by process and location, 1970-2000. Research Paper FPL-RP, v. 602, n. 32, 2001.

INDÚSTRIA BRASILERIA DE ÁRVORES (IBA). Relatório 2019. São Paulo: IBA. Disponível em: https://iba.org/datafiles/publicacoes/relatorios/relatorioiba2019-final.pdf. Acesso em: ago. 2020.

JUVENAL, T. L.; MATTOS, R. L. G. O setor de celulose e papel. In: SÃO PAULO, E. M. de; KALACHE FILHO, J. 
Banco Nacional de Desenvolvimento Econômico e Social 50 anos: histórias setoriais. Rio de Janeiro: Dba, 2002.

LI, H.; LUO, J.; McCARTHY, P. Economic transition and demand pettern: evidence from China's paper and paperboard industry. Georgia Institute of Technology: Atlanta, 2002.

MORRISON, W. M. China’s economic rise: history, trends, challeges, and implications of the United States. Congressional Research Service, 2019. Disponível em: https://www.everycrsreport.com/files/20190625_RL33534_088c5467dd11365dd4ab5f72133db289fa10030f.pdf. Acesso em: out. 2020.

PENA, H. W. A. Brasil e Coréia do Sul: uma análise comparativa da dinâmica das exportaçôes no comércio internacional, 1985-2002. Dissertação (Magister Scientiae) - Programa de Pós-Graduação em Economia, Belém, 2004.

ROCHA, A. P. A.; SOARES, N. S. Desempenho das exportaçóes brasileiras do setor de papel e celulose, entre 1997 e 2011. Informaçóes Econômicas, São Paulo, v. 44, n. 6, 2014.

SOARES, N. S. Análise da competitividade e dos preçóes da celulose e da madeira de eucalipto no Brasil. Tese (Doctor
Scientiae) - Programa de Pós-Graduação em Ciências Florestal, Viçosa, 2010.

SOTO BAQUERO, F. A. Da indústria de papel ao complexo florestal no Brasil: o caminho do corporativismo tradicional ao neocorporatismo. Tese - Instituto de Economia da UNICAMP, Campinas, 1992.

U.S. INTERNATIONAL TRADE COMMISSION USITC. Wood Pulp and Waste paper. Industry \& Trade Summay: Washington, 2002. Disponível em: https://www. usitc.gov/publications/332/pub3490.pdf. Acesso em: out. 2020.

ZAEYEN, A. Estrutura e desempenho do segmento de celulose e papel no Brasil. 1986. $64 \mathrm{f}$. (Tese de mestrado) - Universidade Federal do Rio de Janeiro. Rio de Janeiro, 1986.

ZHUANG, Z.; DING, L.; LI, H. China's pulp and paper industry: a review. Georgia Institute of Technology: Atlanta, 2005. Disponível em: https://cpbis.gatech.edu/files/papers/ CPBIS-FR-08-03\%20Zhuang_Ding_Li\%20FinalReport-China_Pulp_and_Paper_Industry.pdf. Acesso em: out. 2020. 